\title{
Fab-mediated Binding of Drug-dependent Antibodies to Platelets in Quinidine- and Quinine-induced Thrombocytopenia
}

Douglas J. Christie, Patrick C. Mullen, and Richard H. Aster

The Blood Center of Southeastern Wisconsin, Departments of Medicine and Pathology, Medical College of Wisconsin, Milwaukee, Wisconsin 53233

\begin{abstract}
Platelets coated with quinine- or quinidine-induced antibodies form rosettes around protein A-Sepharose beads and normal platelets form rosettes about protein A-Sepharose beads coated with these antibodies. These reactions occurred only in the presence of the sensitizing drug. Platelets also formed rosettes about protein A-Sepharose beads coated with an anti-PI ${ }^{\mathbf{A}}$ antibody, but drug was not required. Formation of rosettes between antibody-coated platelets and protein A-Sepharose was inhibited by $F\left(a b^{\prime}\right)_{2}$ fragments of goat antibody specific for the Fc portion of human IgG, while rosette formation between antibody-coated protein A-Sepharose and platelets was inhibited by $F\left(a b^{\prime}\right)_{2}$ fragments directed against the $F\left(a b^{\prime}\right)_{2}$ portion of the IgG molecule. Since binding of IgG to protein $A$ is known to occur via the Fc region, these findings suggest that binding of drug-induced antibodies to platelets occurs at the Fab domains of the IgG molecule.
\end{abstract}

\section{Introduction}

Drug-dependent antibodies (ddAb) ${ }^{1}$ occur in patients sensitized to certain medications, which are most commonly quinidine or quinine (1). Patients develop profound thrombocytopenia when their platelets become coated with ddAb in the presence of the sensitizing drug. Drugs like quinidine and quinine bind weakly to platelets in the absence of $\operatorname{ddAb}(2,3)$; excess soluble drug is required for maximum ddAb binding to platelets (3); and excess soluble drug fails to displace platelet-bound ddAb $(2,3)$, but it is not yet certain whether ddAb interact with platelets via the Fab or the Fc portion of the antibody molecule. That ddAb binding to platelets might occur via the Fc portion was suggested by two recent studies $(4,5)$, in which $\mathrm{F}\left(\mathrm{ab}^{\prime}\right)_{2}$ fragments of ddAb did not bind demonstrably to platelets in the presence of drug. In the present study, we used intact ddAb and Staphylococcus aureus protein A-Sepharose

\section{Address reprint requests to Dr. Christie. \\ Received for publication 31 July 1984.}

1. Abbreviations used in this paper: anti-Fc and anti- $\mathrm{F}\left(\mathrm{ab}^{\prime}\right)_{2}, \mathrm{~F}\left(\mathrm{ab}^{\prime}\right)_{2}$ fragments of affinity-purified antibodies specific for the $\mathrm{Fc}$ and the $F\left(a b^{\prime}\right)_{2}$ portions of human IgG, respectively; ddAb, drug-dependent antibody; EBP, EDTA-BSA-phosphate-buffered saline; PGE $_{1}$, prostaglandin $E_{1}$; SpA beads, protein A-Sepharose.

\footnotetext{
J. Clin. Invest.

(c) The American Society for Clinical Investigation, Inc.

0021-9738/85/01/0310/05 $\$ 1.00$

Volume 75, January 1985, 310-314
}

(SpA beads) to investigate the molecular orientation with which ddAb bind to platelets. Our findings suggest that this interaction occurs via the Fab portion of the IgG molecule.

\section{Methods}

Chemicals and reagents. Quinine hydrochloride, quinidine hydrochloride, normal human IgG, prostaglandin $\mathrm{E}_{1}\left(\mathrm{PGE}_{1}\right)$, and bovine serum albumin (BSA) (fraction V) were purchased from Sigma Chemical Co. (St. Louis, MO). SpA beads (CL-4B) were obtained from Pharmacia Fine Chemicals (Piscataway, NJ). Affinity purified goat anti-human IgG, $F\left(a b^{\prime}\right)_{2}$ fragments, specific for either the $F c(a n t i-F c)$ or the $F\left(a b^{\prime}\right)_{2}$ $\left(a n t i-F\left(a b^{\prime}\right)_{2}\right)$ portion of the molecule, were from Pel-Freez Biologicals (Rogers, AK).

Patients. Plasma from four patients with confirmed drug-induced immunologic thrombocytopenia (1), two with quinine- and two with quinidine-dependent antibodies (designated PB, GC, LG, and WW, respectively), and plasma containing an anti-PI ${ }^{\wedge 1}$ antibody from a patient with posttransfusion purpura were used. Patients CG, LG, and WW were designated antibodies 1,7 , and 16 , respectively, in a previous report (6).

Rosettes with antibody-coated platelets and SpA. Platelet-rich plasma was isolated from whole blood (anticoagulated with 7.6 mM EDTA) by differential centrifugation as previously described (7). Platelets (1 $\times 10^{8}$ in $200 \mu$ l plasma) were incubated with $500 \mu$ l of normal plasma or patient plasma containing either ddAb or anti-PI ${ }^{\mathbf{A} 1}$ antibody (previously heated at $56^{\circ} \mathrm{C}$ for $30 \mathrm{~min}$ and centrifuged at $12,800 \mathrm{~g}$ for 15 min at $4^{\circ} \mathrm{C}$ in an Eppendorf Micro centrifuge, Brinkmann Instruments, Inc., Westbury, NY). In the case of ddAb, $300 \mu \mathrm{M}$ final concentration of the sensitizing drug or EDTA-BSA-phosphate-buffered saline (EBP) (8 mM EDTA, 1\% BSA wt/vol, $0.1 \mathrm{M} \mathrm{NaH}_{2} \mathrm{PO}_{4}, 0.15 \mathrm{M} \mathrm{NaCl}, \mathrm{pH}$ 7.2) were also added. The mixture was incubated for $30 \mathrm{~min}$ at room temperature with gentle rotation. Some experiments were modified by the addition of $20 \mathrm{ng} / \mathrm{ml} \mathrm{PGE}$ and/or the use of lower drug concentrations $(10-30 \mu \mathrm{M})$. Cells were then washed twice in EBP that contained $1 \mathrm{mM}$ sensitizing drug (if the initial mixture contained drug) and resuspended in $200 \mu \mathrm{l} \mathrm{EBP}$ containing $300 \mu \mathrm{M}$ drug (all samples). Rosettes were formed by mixing $20 \mu$ EBP that contained $300 \mu \mathrm{M}$ drug, $20 \mu \mathrm{l}$ antibody-coated platelets $\left(1 \times 10^{7}\right)$, and $10 \mu \mathrm{l} \mathrm{SpA}$ beads (packed volume diluted 1:10 in EBP) in a 96-well flat bottom plate (Costar, Cambridge, MA) pretreated with 5\% BSA in EDTA-phosphatebuffered saline (PBS) for $30 \mathrm{~min}$ and rinsed once with EBP. Rosette formation occurred over $12 \mathrm{~h}$ at $4^{\circ} \mathrm{C}$ and was evaluated microscopically by gently adding $5 \mu \mathrm{l}$ of each reaction mixture to $20 \mu \mathrm{l}$ EBP on a standard microscope slide with coverslip.

Partial purification of platelet antibodies. Plasma (50 ml) containing ddAb was incubated with $300 \mu \mathrm{M}$ sensitizing drug and $2 \times 10^{10}$ platelets (previously washed three times in EDTA-PBS, pH 7.3) in a final volume of $55 \mathrm{ml}$ for $30 \mathrm{~min}$ at room temperature. After three washes with $1 \mathrm{mM}$ drug in EDTA-PBS, the antibodies were eluted from the platelets with chloroform (8) and dialyzed exhaustively against PBS. IgG concentrations were determined by electroimmunoassay (9) and ranged between 100 and $200 \mu \mathrm{g} / \mathrm{ml}$. The fraction of the IgG 
consisting of ddAb was determined by incubating samples of the eluate (containing $1 \mu \mathrm{g}$ of total $\mathrm{IgG}$ ) in the presence and absence of $1 \mathrm{mM}$ sensitizing drug with increasing numbers of washed platelets $\left(5 \times 10^{6}-\right.$ $5 \times 10^{7}$ platelets $\left./ \mu \mathrm{l}\right)$ for $20 \mathrm{~min}$ at room temperature. Mixtures were then centrifuged at $12,800 \mathrm{~g}$ for $2 \mathrm{~min}$, and supernatants were analyzed for IgG content by electroimmunoassay (3). The difference in IgG content of the eluate absorbed with platelets in the presence and absence of drug ranged between 20 and $40 \%$ of the total IgG and was assumed to represent drug-dependent platelet antibody. Eluates of the anti-PI ${ }^{\wedge 1}$ antibody were similarly prepared without the use of drug and their content of specific IgG determined by absorption with $\mathrm{Pl}^{\wedge 1}$. positive and $\mathrm{PI}^{\wedge 1}$-negative platelets.

Rosettes with antibody-coated SpA beads and platelets. SpA beads ( $100 \mu \mathrm{l}$ of a 1:10 dilution of packed beads) were incubated either with eluates containing $150 \mu \mathrm{g} \mathrm{IgG}$, of which $19-27 \%$ was ddAb or anti$\mathrm{Pl}^{\wedge 1}$ antibody, or with $150 \mu \mathrm{g}$ of normal human IgG for $30 \mathrm{~min}$ at room temperature, washed twice with EBP, and resuspended in 100 $\mu \mathrm{l}$ EBP. Rosettes were induced as described above by incubating $10 \mu \mathrm{l}$ antibody- or normal IgG-coated SpA beads with $1 \times 10^{7}$ platelets, followed by two washes in EDTA-PBS and resuspension in $20 \mu \mathrm{l} \mathrm{EBP.}$ In the case of ddAb, $1 \mathrm{mM}$ sensitizing drug was present in the wash solutions.

Inhibition of rosette formation. Antibody-coated platelets were resuspended in $100 \mu \mathrm{l}$ EBP that contained $1 \mathrm{mM}$ sensitizing drug, and $50 \mu \mathrm{l}$ of this suspension $\left(5 \times 10^{7}\right.$ platelets $)$ was incubated with $50 \mu \mathrm{l}$ of the $F\left(a b^{\prime}\right)_{2}$ fragments of anti-Fc or anti-F(ab') antibody at various dilutions $(5-500 \mu \mathrm{g} / \mathrm{ml}$ final concentration) for $30 \mathrm{~min}$ at room temperature before addition of $\mathrm{SpA}$ beads. Rosette formation was induced and visualized as described above. Inhibition of rosette formation between antibody-coated SpA beads and platelets was studied in the same way, except that the blocking reagent was incubated first with the SpA beads and nonsensitized platelets were then added.

\section{Results}

Binding of antibody-coated platelets to $\mathrm{SpA}$ beads. Platelets coated with quinine- or quinidine-induced antibodies in the presence of sensitizing drug $(300 \mu \mathrm{M})$ readily formed rosettes about the SpA beads (Fig. $1 A$ ). Pharmacologic concentrations of drug $(10-30 \mu \mathrm{M})$ also induced rosette formation in this system (not shown). Elimination of drug from final incubation with SpA beads had little or no effect on rosette formation.

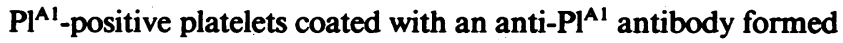
rosettes with $\mathrm{SpA}$ beads indistinguishable from those seen with ddAb-coated platelets. Frequently, platelets appeared to bind to each other as well as to the beads, forming layers around the beads. It is unlikely that this apparent platelet-platelet binding was due to aggregation, since it occurred in the presence of $8 \mathrm{mM}$ EDTA and, in some experiments, $20 \mathrm{ng} /$ ml $\mathrm{PGE}_{1}$, which is a potent inhibitor of aggregation (10). Platelets incubated with ddAb in the absence of drug failed to form rosettes (Fig. $1 C$ ). No rosettes formed between SpA

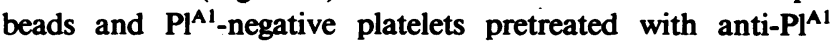
antibody. Negative reactions always appeared as shown in Fig. $1 C$. Therefore, this figure will be referred to in subsequent experiments where rosettes failed to form.

Binding of platelets to antibody-coated SpA beads. To investigate the molecular orientation of ddAb bound simultaneously to platelets and $\mathrm{SpA}$ beads, partially purified ddAb was immobilized by its Fc region on SpA beads and then incubated with platelets in the presence and absence of the sensitizing drug $(300 \mu \mathrm{M})$. Rosettes formed readily between platelets and ddAb-coated SpA beads, but only when drug was included in the incubation mixture. In contrast to the multi- layered binding of antibody-coated platelets to $\mathrm{SpA}$ beads (Fig. $1 A$ ), unsensitized platelets generally became bound to antibodycoated SpA beads in a monolayer (Fig. $1 B$ ). Rosettes essentially identical to those shown in Fig. $1 B$ formed when $\mathrm{PI}^{\mathrm{A}}$-positive platelets were incubated with SpA beads coated with the anti$\mathrm{PI}^{\wedge 1}$ antibody. Platelets failed to form rosettes with SpA beads coated with normal human IgG incubated in the presence or absence of drug, and $\mathrm{PI}^{\wedge 1}$-negative platelets did not form rosettes with $\mathrm{SpA}$ beads coated with anti-P1 ${ }^{\wedge i}$ antibody (Fig. 1 $C$ ). These findings suggested that rosette formation was associated with the binding of antibody by its Fc end to SpA beads and its Fab end to platelets.

Inhibition of rosette formation with anti-Fc and anti-F $\left(a b^{\prime}\right)_{2}$. To further test this hypothesis, attempts were made to inhibit rosette formation with affinity purified $F\left(a b^{\prime}\right)_{2}$ fragments directed against the $F c$ and $F\left(a b^{\prime}\right)_{2}$ regions of human IgG. When ddAb absorbed to SpA beads were incubated with one or the other of the two blocking antibodies, anti-F $\left(\mathrm{ab}^{\prime}\right)_{2}$ at 5-50 $\mu \mathrm{g} /$ $\mathrm{ml}$ prevented rosette formation by subsequently added platelets and drug while anti-Fc failed to inhibit even at $500 \mu \mathrm{g} / \mathrm{ml}$ (Table I). The same was true of rosette formation between platelets and SpA beads coated with anti-PIA ${ }^{\mathbf{A}}$. In the converse experiment, when platelets were first coated with the anti-PI ${ }^{\mathbf{A}}$ antibody or $\mathrm{ddAb}$ and then incubated with blocking antibody at $50 \mu \mathrm{g} / \mathrm{ml}$, anti-Fc inhibited rosette formation with subsequently added $\mathrm{SpA}$ beads while the same quantity of anti$F\left(a b^{\prime}\right)_{2}$ was ineffective (Table I). However, rosette formation was blocked with 10 times this amount of anti- $F\left(a b^{\prime}\right)_{2}$.

Thus, anti-Fc effectively blocks rosette formation by platelets coated with ddAb or anti-PI ${ }^{A 1}$ antibody but fails to do so when nonsensitized platelets are incubated with antibody-coated SpA beads. Conversely, small quantities of anti- $F\left(a b^{\prime}\right)_{2}$ effectively block rosette formation when nonsensitized platelets are incubated with antibody-coated SpA beads, but not when the antibodies are first bound to platelets, except at very high concentration.

\section{Discussion}

Our findings suggest that ddAb bind to platelets by their Fab combining sites in the presence of drug, leaving the $\mathrm{Fc}$ portion of the antibody molecules free for attachment to SpA beads. This conclusion is supported by the following observations: $(a)$ in all experiments, an anti- $\mathrm{Pl}^{\mathrm{A} 1}$ antibody behaved identically to the four ddAb studied; $(b)$ platelet-platelet binding was seen when rosettes were formed with antibody-coated platelets and $\mathrm{SpA}$ beads, presumably because the divalent antibody molecules were capable of attaching simultaneously to more than one platelet; and $(c)$ rosette formation was blocked preferentially by incubating ddAb-coated platelets with antibody directed against the Fc portion of the IgG molecule or by incubating ddAb-coated SpA beads with antibody directed against the $\left.\mathrm{F}(\mathrm{ab})^{\prime}\right)_{2}$ region. We are uncertain why high concentrations (500 $\mu \mathrm{g} / \mathrm{ml}$ ) of anti- $\mathrm{F}\left(\mathrm{ab}^{\prime}\right)_{2}$ inhibited rosette formation between antibody-coated platelets and SpA beads (Table I). Extremely high levels of anti- $\mathrm{F}\left(\mathrm{ab}^{\prime}\right)_{2}$ might competitively displace bound $\mathrm{ddAb}$ and anti-PIA1 antibody from the platelet surface. This possibility is currently being investigated.

McVeigh and Chesterman (11) found that platelets coated with a single quinine-induced antibody in the presence of drug were preferentially retained on a column of SpA beads, but 

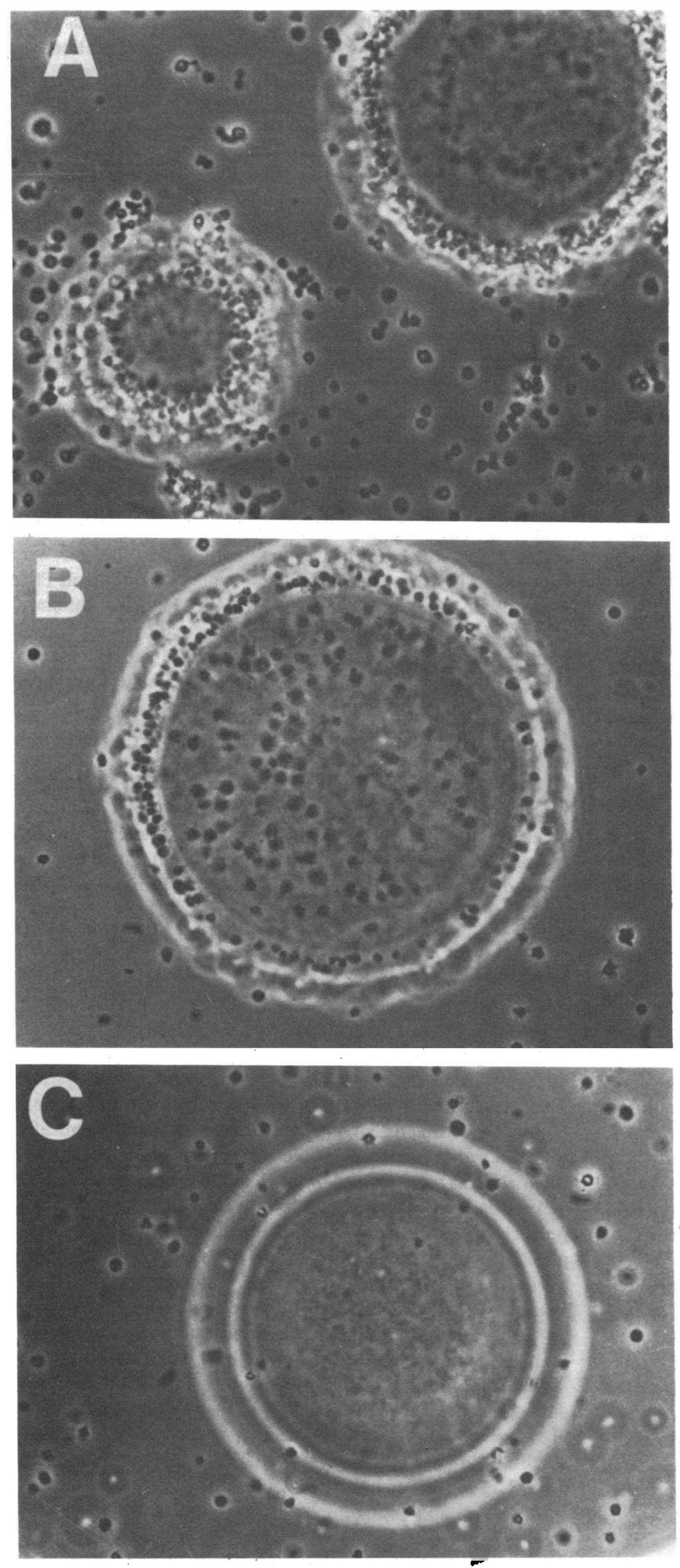

Figure 1. Rosette formation between platelets, SpA beads, and antibody. $(A)$ Pattern observed when antibody-coated platelets were incubated with SpA beads. $X$ 500. (B) Pattern seen when antibody-coated SpA beads were incubated with nonsensitized platelets in the presence of drug. Note the relative absence of platelet layering. $(C)$ Typical pattern seen when antibody-coated SpA beads were incubated with nonsensitized platelets in the absence of drug or when rosette formation was inhibited by $F\left(a b^{\prime}\right)_{2}$ fragments of blocking antibodies (see text). Results shown are typical of those obtained with four

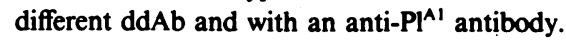


Table I. Effect of Anti-Fc and Anti-F(ab') ${ }_{2}$ on Rosette Formation*

\begin{tabular}{|c|c|c|c|c|c|c|c|c|c|c|}
\hline \multirow{2}{*}{ 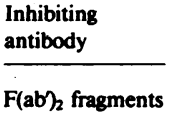 } & \multicolumn{5}{|c|}{ Rosette formation with antibody-coated SpA beads } & \multicolumn{5}{|c|}{ Rosette formation with antibody-coated platelets } \\
\hline & PB & GC & LG & $w w$ & $\mathbf{P I}^{\mathbf{\Lambda}}$ & PB & GC & LG & ww & $\mathbf{P}^{\mathbf{A}^{\wedge}}$ \\
\hline \multicolumn{11}{|l|}{$\mu g / m l$} \\
\hline \multicolumn{11}{|l|}{ Anti-Fc } \\
\hline 5 & + & + & + & + & + & + & + & + & + & + \\
\hline 50 & + & + & + & + & + & - & - & - & - & - \\
\hline 500 & + & + & + & + & + & - & - & - & - & - \\
\hline \multicolumn{11}{|l|}{ Anti-F $\left(a b^{\prime}\right)_{2}$} \\
\hline 5 & + & - & + & + & - & + & + & + & + & + \\
\hline 50 & - & - & - & - & - & + & + & + & + & + \\
\hline 500 & - & - & - & - & - & - & - & - & - & - \\
\hline
\end{tabular}

\footnotetext{
* Results are graded plus or minus based on the percentage of surface area of SpA beads covered with platelets. Plus (+) indicates that $25-100 \%$ of the bead surface was covered with platelets, and minus $(-)$ indicates that virtually no platelets were attached to SpA beads. No more than 10-20 platelets per bead were seen in negative experiments, while several hundred platelets per bead were seen in positive experiments.
}

they did not comment on the possible relationship of this finding to the mechanism of drug-antibody-platelet interaction. Chong et al. (12) recently described immunoprecipitation of a quinidine-induced antibody complexed to glycoproteins Ib and IX by intact $S$. aureus cells in the presence of drug. These reports, together with our findings, all indicate that the ddAb molecule is capable of reacting simultaneously with protein A (either Sepharose bound or bacterial cell wall bound) and a platelet binding site in the presence of drug. While it is conceivable that one portion of the Fc region of ddAb reacts with platelets and a different Fc domain reacts with protein $A$, the most plausible explanation for these observations is that ddAb bind to a site or sites on the platelet membrane via the Fab portion of the antibody molecule, thus leaving the Fc region available for protein $A$ binding.

Recent studies by van Leeuwen et al. (4) and Lerner et al. (5), using two different quinidine-induced antibodies, failed to demonstrate binding of $F\left(a b^{\prime}\right)_{2}$ fragments of these antibodies to platelets in the presence of drug, which led both groups of investigators to conclude that ddAb bind to platelets via the Fc portion of the antibody molecule. However, neither report showed that the $F\left(a b^{\prime}\right)_{2}$ fragments retained their ability to interact with drug. In fact, we are unaware of any report showing that $\mathrm{Fab}$ or $\mathrm{F}\left(\mathrm{ab}^{\prime}\right)_{2}$ fragments of ddAb are capable of binding to drug or platelets. It seems possible that the Fc portion of the ddAb molecule somehow stabilizes the $F\left(a b^{\prime}\right)_{2}$ portion and that digestion with an enzyme like pepsin destroys the binding activity of the Fab combining sites. Alternatively, the methods used by van Leeuwen et al. (4) and Lerner et al. (5) (indirect immunofluorescence and indirect labeling with ${ }^{125}$ I-SpA after incubation of the platelets with rabbit antihuman IgG) may not have been sensitive enough to detect platelet-bound $F\left(a b^{\prime}\right)_{2}$ fragments that were derived from ddAb.

Ackroyd (13) proposed a mechanism for the drug-ddAbplatelet reaction in which drug, acting as a hapten, modified a platelet constituent to produce a hapten-carrier complex which induces antibody formation. Under this hypothesis, subsequent exposure of a sensitized individual to drug would lead to drugcoated platelets that are then bound by ddAb. An alternate model was proposed independently by Miescher and Miescher
(14) and Shulman (15) in which some macromolecule unrelated to platelets, such as a plasma protein, is modified by drug to produce the hapten-carrier complex that induces antibody production. When a sensitized individual is rechallenged with drug, drug and antibody combine first to form soluble complexes which then bind to platelets in a second step ("innocent bystander" reaction) $(16,17)$. Shulman (2) provided experimental support for the latter hypothesis by showing that quinidine binds only weakly to platelets and would, therefore, be unlikely to form complexes capable of inducing antibody, and that high concentrations of drug do not displace plateletbound ddAb, as would be expected in a conventional hapten inhibition reaction. We confirmed and extended these observations by showing that even platelets coated with a million molecules of drug do not express ddAb binding sites unless excess soluble drug is present (3). Although these findings supported the "innocent bystander" mechanism for drugddAb-platelet interaction in drug-induced immunologic thrombocytopenia, they did not rule out the possibility that drug reacts first with platelets to induce a reversible confirmational change in the membrane, which would result in expression of a "neoantigen" to which ddAb then binds (3).

Our studies show that platelets coated with ddAb in the presence of drug at concentrations that can be achieved therapeutically form rosettes with SpA beads. Since our data support the possibility that ddAb bind to platelets via their Fab combining sites, it is reasonable to conclude that, at the onset of thrombocytopenia, circulating platelets are directly recognized as an antigen by ddAb in the presence of drug.

These observations seem most consistent with the following model for drug-ddAb-platelet binding: platelets coated with drug express an unstable neoantigen which is stabilized upon interaction with the Fab domains of ddAb (3). We and others previously showed that the expression of this putative platelet neoantigen is dependent on the continued presence of drug in the suspension medium. That is, platelets pretreated with drug and then washed do not express binding sites for ddAb, and bound ddAb can readily be removed from platelets by washing in the absence of drug (3). However, ddAb-coated platelets retain significantly more drug after multiple washes than 
uncoated platelets (3). The molecular nature of the putative neoantigen(s) and the mechanism(s) by which it is expressed are subjects of current investigation.

\section{Acknowledgments}

We thank Julie Fellenz for assistance in processing this manuscript.

This work was supported in part by New Investigator Research Award HL-31324 and grant HL-13629 from the National Heart, Lung, and Blood Institute, and by American Heart Association/Wisconsin Affiliate Grant-in-Aid 83-GA-37.

\section{References}

1. Aster, R. H. 1983. Thrombocytopenia due to enhanced platelet destruction. In Hematology. W. Williams, E. Beutler, A. Erslev, and M. Lichtman, editors. McGraw-Hill, Inc., New York. 1326-1359.

2. Shulman, N. R. 1958. Immunoreactions involving platelets: I. A steric and kinetic model for formation of a complex from a human antibody, quinidine as a haptene, and platelets; and for fixation of complement by the complex. J. Exp. Med. 107:665-690.

3. Christie, D. J., and R. H. Aster. 1982. Drug-antibody-platelet interaction in quinine- and quinidine-induced thrombocytopenia. $J$. Clin. Invest. 70:989-998.

4. van Leeuwen, E. F., C. P. Engelfrieft, and A. E. G. Kr. von dem Borne. 1982. Studies on quinine- and quinidine-dependent antibodies against platelets and their reaction with platelets in the Bernard-Soulier syndrome. Br. J. Haematol. 51:551-560.

5. Lerner, W., D. Faig, and S. Karpatkin. 1982. Mechanisms of drug-induced immunologic thrombocytopenic purpura (DITP). Blood. 60(Suppl. 1):188a. (Abstr.)

6. Christie, D. J., R. W. Weber, P. C. Mullen, J. M. Cook, and R. H. Aster. 1984. Structural features of the quinidine and quinine molecules necessary for binding of drug-induced antibodies to human platelets. J. Lab. Clin. Med. 104:730-740.
7. Aster, R. H., and S. E. Enright. 1969. A platelet and granulocyte membrane defect in paroxysmal nocturnal hemoglobinuria: usefulness for the detection of platelet antibodies. J. Clin. Invest. 48:1190-1210.

8. Branch, D. R., A. L. Sy Siok Hian, and L. D. Petz. 1982. A new elution procedure using chloroform, a nonflammable organic solvent. Vox. Sang. 42:46-53.

9. Kunicki, T. J., M. B. Koenig, S. M. Kristopeit, and R. H. Aster. 1982. Direct quantitation of platelet-associated IgG by electroimmunoassay. Blood. 60:54-58.

10. Sinha, A. K., S. J. Shattil, and R. W. Colman. 1977. Cyclic AMP metabolism in cholesterol-rich platelets. J. Biol. Chem. 252:33103314.

11. McVeigh, D. J., and C. N. Chesterman. 1981. The use of a protein A-Sepharose column in the detection of platelet-associated IgG. Thromb. Res. 23:559-562.

12. Chong, B. H., M. C. Berndt, J. Koutts, and P. A. Castaldi. 1983. Quinidine-induced thrombocytopenia and leukopenia: demonstration and characterization of distinct antiplatelet and antileukocyte antibodies. Blood. 62:1218-1223.

13. Ackroyd, J. F. 1953. Allergic purpura, including purpura due to foods, drugs and infections. Am. J. Med. 14:605-632.

14. Miescher, P., and R. Miescher. 1952. Die Sedormid-Anaphlaxie. Schweiz. Med. Wochenschr. 82:1279-1281.

15. Shulman, N. R. 1963. Mechanism of blood cell damage by adsorption of antigen-antibody complexes. In Immunopathology. Third International Symposium. P. Grabar and P. Miescher, editors. Schwabe \& Co., La Jolla, CA. 338-352.

16. Croft, J. D., Jr., and R. I. Weed. 1968. Coombs'-test positive induced by drugs: mechanisms of immunologic reactions, and red cell destruction. Ann. Intern. Med. 68:176-187.

17. Shulman, N. R., and J. V. Jordan. 1982. Platelet immunology. In Hemostasis and Thrombosis: Basic Principles and Clinical Practice. R. Colman, J. Hirsch, V. Marder, and E. Salzman, editors. J. B. Lippincott Co., Philadelphia. 274-342. 